\title{
Article \\ Adult Medulloblastoma Demographic, Tumor and Treatment Impact since 2006: A Canadian University Experience
}

\author{
Maria Camila Quinones ${ }^{1, *}$, Karl Bélanger ${ }^{2}$, Émilie Lemieux Blanchard ${ }^{2}$, Bernard Lemieux ${ }^{2}$, Jean-Paul Bahary ${ }^{2}$, \\ Laura G. Masucci ${ }^{2}$, David Roberge ${ }^{2}$ D , Cynthia Menard ${ }^{2}$, Carole Lambert ${ }^{2}$, France Berthelet ${ }^{2}$, \\ Robert Moumdjian ${ }^{2}$ and Marie Florescu ${ }^{2}$
}

1 CHUM Research Centre (CrCHUM), Montreal, QC H2X 0A9, Canada

2 CHUM Research Centre (CrCHUM), Department of Hematology and Oncology, Centre Hospitalier de l'Université de Montréal (CHUM), Montreal, QC H2X 3E4, Canada; karl.belanger.chum@ssss.gouv.qc.ca (K.B.); emilie.lemieux-blanchard.chum@ssss.gouv.qc.ca (É.L.B.); bernard.lemieux.chum@ssss.gouv.qc.ca (B.L.); jean-paul.bahary.chum@ssss.gouv.qc.ca (J.-P.B.); g.laura.masucci.chum@ssss.gouv.qc.ca (L.G.M.); david.roberge.chum@ssss.gouv.qc.ca (D.R.); cynthia.menard@umontreal.ca (C.M.); carole.lambert.chum@ssss.gouv.qc.ca (C.L.); france.berthelet@umontreal.ca (F.B.); robert.a.moumdjian.med@ssss.gouv.qc.ca (R.M.); marie.florescu.med@ssss.gouv.qc.ca (M.F.)

* Correspondence: maria.camila.quinones@umontreal.ca

\section{check for} updates

Citation: Quinones, M.C.; Bélanger, K.; Lemieux Blanchard, É.; Lemieux, B.; Bahary, J.-P.; Masucci, L.G.;

Roberge, D.; Menard, C.; Lambert, C.; Berthelet, F.; et al. Adult

Medulloblastoma Demographic, Tumor and Treatment Impact since 2006: A Canadian University

Experience. Curr. Oncol. 2021, 28 ,

3104-3114. https://doi.org/10.3390/ curroncol28040271

Received: 16 July 2021

Accepted: 11 August 2021

Published: 14 August 2021

Publisher's Note: MDPI stays neutral with regard to jurisdictional claims in published maps and institutional affiliations.

Copyright: (c) 2021 by the authors. Licensee MDPI, Basel, Switzerland. This article is an open access article distributed under the terms and conditions of the Creative Commons Attribution (CC BY) license (https:/ / creativecommons.org/licenses/by/ $4.0 /)$.

\begin{abstract}
Medulloblastoma is an aggressive primary brain tumor that is extremely rare in adults; therefore, prospective studies are limited. We reviewed the information of all MB patients treated at the CHUM between 2006 and 2017. We divided our cohort by age and further divided adult patients (53\%) in two groups, those diagnosed between 2006-2012 and 2013-2017. In our adult population, median follow up was 26 months and SHH-activated MB comprised 39\% of tumors. Adult 5yOS was $80 \%$ and first-line therapy led to a $5 y$ PFS of $77 \%$. The absence of radiosensitizing chemotherapy $(100 \%$ vs. $50 \% ; p=0.033)$ negatively influenced 5yPFS. $96 \%$ of adult patients received radiotherapy and $48 \%$ of them received concomitant radiosensitizing chemotherapy. Complete surgical resection was performed on $85 \%$ of adults, but the extent of resection did not have a discernable impact on survival and did not change with time. Adjuvant chemotherapy did not clearly affect prognosis (5yOS $80 \%$ vs. $67 \%, p=0.155$; 5yPFS $78 \%$ vs. $67 \%, p=0.114$ ). From $2006-2012$, the most common chemotherapy regimen (69\%) was Cisplatinum, Lomustine and Vincristine, which was replaced in 2013 by Cisplatinum, Etoposide and Cyclophosphamide (77\%) with a trend for worse survival. Nine patients recurred and seven of these (78\%) were treated with palliative chemotherapy. In conclusion, we did not identify prognostic demographic or tumor factors in our adult MB population. The presence of radiosensitizing chemotherapy was associated with a more favorable PFS. Cisplatinum, Lomustine and Vincristine regimen might be a better adjuvant chemotherapy regimen.
\end{abstract}

Keywords: medulloblastoma; adult medulloblastoma; chemotherapy; prognostic factors

\section{Introduction}

Medulloblastoma (MB) is the most common malignant brain tumor of childhood, accounting for nearly $20 \%$ of all primary central nervous system (CNS) tumours amongst patients younger than 19 years of age. It is extremely rare in adults, representing less than $1 \%$ of intracranial tumors in this population [1,2]. The incidence rate of MB in adults is 0.5 cases/million, making prospective studies in this age group remarkably limited and controlled randomised trials non-existent [3]. Consequently, the available literature largely focuses on paediatric $\mathrm{MB}$ and controversy remains regarding adult prognostic factors and standard-of-care treatment.

Literature suggests that childhood and adult MB differ clinically and phenotypically [4-6]. Thus, evidence indicates that the different factors that affect patients' prognosis 
vary according to their age. Notably, adults tend to have numerous comorbidities when compared with children. These differences have brought the scientific community to question that adults generally receive the same therapies developed for children. In this study, we aimed to determine the survival of the adult MB patients treated at our centre, as well as to evaluate their prognostic factors and treatment efficacy.

\section{Materials and Methods}

\subsection{Data Source and Patient Selection}

We conducted a retrospective study of all $\mathrm{MB}$ patients treated at the Centre hospitalier de l'Université de Montréal (CHUM) using our tumor registry and electronic medical records (EMR). First, through our tumour registry, which actively collects data from patients seen in the cancer center, we identified patients with MB diagnosed between 2006 and 2017. From this database, we extracted age at MB diagnosis, sex, family history of central nervous system (CNS) tumors, tumour histology and molecular markers, progression dates, date of last contact, date of death and treatment regimens received. We then completed this information using our general and oncology EMRs.

The study protocol was submitted and approved by the Research Ethics Committee of the CHUM Research Centre (CRCHUM).

Of all 50 patients identified by our tumour registry, 49 were included in the study. One was excluded from the analysis as he only made one visit to our emergency department for a reason unrelated to his MB diagnosis. All patients identified had histologically confirmed MB. The median follow-up for adult patients was 26 months, with a range of 3 months to 7 years.

Of the patients identified, 23 were children and 26 were adults. Children were typically only seen in our cancer centre for radiotherapy and thus had more limited follow-up information.

\subsection{Patient Distribution}

As observed in Figure 1, we divided the adults (18 years of age and older) in two sub-groups, those diagnosed between 2006 and 2012 and those diagnosed between 2013 and 2017. The cut-off of 2012 was based on a change in the adjuvant chemotherapy regimen used. Before 2013, a Cisplatinum and Lomustine-based regimen was most frequently prescribed; whereas after this date, a Cisplatinum and Etoposide-based regimen predominated. This change took place as evidence suggesting an advantage of the new topoisomerase II inhibitor (TOP2i)-based regimen compared to the old nitrosourea-based one became more available. Notably, a study conducted by Silvani et al. and published at the end of 2011 concluded that patients exposed to this new regimen experienced "considerably lower chemotherapy-related toxicity, compared with that experienced by patients who received other treatments" [3].

\subsection{Outcomes}

The primary outcome of this study was the demographic, tumor and treatment characteristics specific to our population and their impact on overall and progress-free survival. We compared these findings to the paediatric and adult populations that have previously been described and aimed to recommend a first line treatment regimen for adults.

\subsection{Statistical Analysis}

Overall survival (OS) was defined as the time from diagnosis until death by any cause. Progress-free survival (PFS) was defined as the time from diagnosis until the first recurrence, or death if no recurrence had been confirmed previously. The date of diagnosis was determined as the date of tumour extraction. Recurrence was defined by a significant increase in measurable disease by imaging studies, or the development of a new tumour locus, including local or distant metastasis. The Kaplan-Meier method was used to assess OS and PFS. 


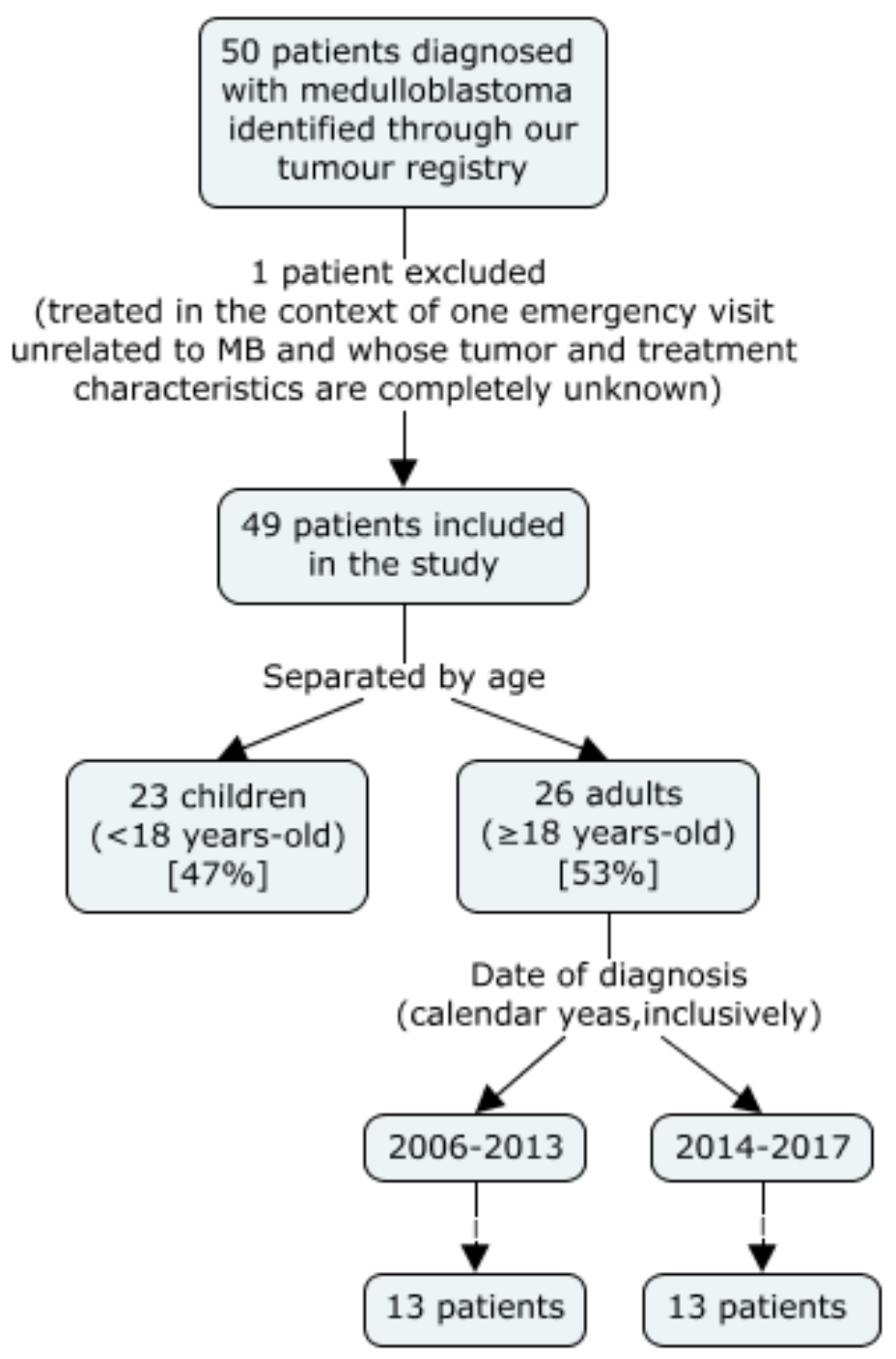

Figure 1. Patient Selection and Distribution.

Patient characteristics (age and gender), tumour characteristics (histopathology, molecular subgroup and extent of disease), and treatment-related factors (extent of surgical resection, radiotherapy use with and without concomitant chemotherapy, adjuvant chemotherapy use and its different agents) were analyzed as potential prognostic factors using the univariate log-rank method. A $p$-value $<0.05$ was considered statistically significant. Due to the limited population size of our study, we were unable to define prognostic variables by a multivariate analysis.

The IBM SPSS Statistics software (IBM Corp. Released 2017. IBM SPSS Statistics for Windows, Version 25.0. IBM Corp, Armonk, NY, USA) was used for statistical analysis.

\section{Results}

\subsection{Patient and Tumour Characteristics}

Of our 49 patients, 23 were children (47\%) and 26 were adults (53\%). Two patients were younger than 3 years of age (4\%) and nine were aged between 40 and $60(18 \%$ of all patients and $35 \%$ of adult patients). There were no patients older than 60 years. The median age of our adult cohort was 29 (18 to 53 years-old) and the median follow-up was 26 months. This is remarkably similar to some of the largest multicentre studies available [7-11]. The demographic, tumour and treatment characteristics of the population in our study are summarized in Table 1. 
Table 1. Patient, Tumor and Summarized Treatment Characteristics.

\begin{tabular}{|c|c|c|c|c|}
\hline & & $\begin{array}{l}\text { All Participants } \\
\qquad N=49(\%)\end{array}$ & $\begin{array}{c}\text { Adults } \\
N=26(\%)\end{array}$ & $\begin{array}{l}\text { Children } \\
\mathrm{N}=23(\%)\end{array}$ \\
\hline \multicolumn{5}{|c|}{ Demographic Characteristics } \\
\hline \multicolumn{2}{|c|}{ Median Age in Years (range) } & $19(0-53)$ & $29(18-53)$ & $7(0-16)$ \\
\hline \multirow{2}{*}{ Sex } & Male & $36(73)$ & $19(73)$ & $17(74)$ \\
\hline & Female & $13(27)$ & $7(27)$ & $6(26)$ \\
\hline \multirow{3}{*}{ Family history of CNS cancer } & Yes & - & - & - \\
\hline & No & $15(31)$ & $15(58)$ & - \\
\hline & Unknown & $34(69)$ & $11(42)$ & $23(100)$ \\
\hline \multirow{2}{*}{ Comorbidities } & Yes & $4(8)$ & $4(15)$ & - \\
\hline & No & $45(92)$ & $22(85)$ & $23(100)$ \\
\hline \multicolumn{5}{|c|}{ Tumor Characteristics } \\
\hline \multirow{3}{*}{ Histopathology } & Classic (CMB) & $26(53)$ & $11(42)$ & $15(65)$ \\
\hline & Desmoplastic/nodular (DNMB) & $16(33)$ & $12(46)$ & $4(17)$ \\
\hline & Large cell/anaplastic (LCAMB) & $7(14)$ & $3(12)$ & $4(17)$ \\
\hline \multirow{5}{*}{$\begin{array}{l}\text { Molecular } \\
\text { Subgroup * }\end{array}$} & SHH-activated (SHH-MB) & $13(27)$ & $10(39)$ & $3(13)$ \\
\hline & SHH- activated: TP53-mutant & $1(2)$ & - & $1(4)$ \\
\hline & SHH activated: TP53-wildtype & $12(25)$ & $10(39)$ & $2(9)$ \\
\hline & Non-WNT/non-SHH ** & $25(51)$ & $11(42)$ & $14(61)$ \\
\hline & Unknown & $11(22)$ & $5(19)$ & $6(26)$ \\
\hline \multirow{4}{*}{$\begin{array}{l}\text { Stage at } \\
\text { Diagnosis }\end{array}$} & M0 & $30(61)$ & $14(54)$ & $16(70)$ \\
\hline & M2 & $3(6)$ & $1(4)$ & $2(9)$ \\
\hline & M3 & $3(6)$ & - & $3(13)$ \\
\hline & Unknown & $13(27)$ & $11(42)$ & $2(9)$ \\
\hline \multirow{3}{*}{$\begin{array}{l}\text { Cerebral Spinal Fluid (CSF) } \\
\text { at Diagnosis }\end{array}$} & Positive & $1(2)$ & $1(4)$ & - \\
\hline & Negative & $11(22)$ & $6(23)$ & $5(22)$ \\
\hline & Unknown & $37(76)$ & $19(73)$ & $18(78)$ \\
\hline \multirow{2}{*}{ Tumor Location } & Cerebellum & $40(82)$ & $23(88)$ & $17(74)$ \\
\hline & Brainstem & $9(18)$ & $3(12)$ & $6(26)$ \\
\hline \multicolumn{5}{|c|}{ Treatment Characteristics } \\
\hline \multirow{2}{*}{$\begin{array}{l}\text { Surgical macroscopic } \\
\text { resection }\end{array}$} & Complete & $43(88)$ & $22(85)$ & $21(91)$ \\
\hline & Partial & $6(12)$ & $4(15)$ & $2(9)$ \\
\hline \multirow{3}{*}{ Radiotherapy } & None & $1(2)$ & $1(4)$ & - \\
\hline & Alone & $25(51)$ & $13(50)$ & $12(52)$ \\
\hline & With concomitant chemotherapy & $23(47)$ & $12(46)$ & $11(48)$ \\
\hline \multirow{3}{*}{$\begin{array}{l}\text { Adjuvant } \\
\text { Chemotherapy }\end{array}$} & Yes & $22(45)$ & $21(81)$ & $1(4)$ \\
\hline & No & $5(10)$ & $5(19)$ & - \\
\hline & Unknown **** & $22(45)$ & - & $22(96)$ \\
\hline
\end{tabular}

Percentages might not add up to 100 because of rounding. * There were no patients with a WNT-activated pathway tumour (WNT-MB). ** Equivalent to Subgroups 3 and $4 .{ }^{* * *}$ Information according to the medical record. There were no patients with Stage M1 or M4 disease at diagnosis. ${ }^{* * *}$ Information not available due to patients being followed at a paediatric centre (only intended regimen was available in our EMRs).

In a preliminary analysis, we compared survival for patients between 18 and 39 years of age to those between 40 to 60 years of age. Because there was no significant difference between the two groups, we decided to study all adults as one group.

Contrary to the observed positive prognostic value of female sex in the paediatric population, the effect of sex on the progression of adult disease remains controversial [12-14]. Our cohort was composed mainly of men (73\%), which is consistent with available literature $[1,3,5,6,8-10,12,15-17]$, and sex had no discernable impact on OS or PFS.

In children, histology clearly is of prognostic significance. In adults, there is consensus that LCAMB is associated with worse outcomes, but there is contradictory data regarding $\mathrm{CMB}$ and $\mathrm{DNMB}$, which are the most frequent histologic variants [5,8,15,18-20]. Despite being more common in adults than in children, $\mathrm{DNMB}^{\prime}$ s prognostic significance has not been clearly established in the adult population [5,11,21]. In our study, CMB and DNMB were the most frequent histological variants ( $42 \%$ and $46 \%$ respectively) and histopathology did not significantly influence OS or PFS. However, differences in therapy may have influenced this result because patients with $\mathrm{CMB}$ more often received $\mathrm{RT}$ with concomitant 
chemotherapy and a nitrosourea-based adjuvant chemotherapy regimen, compared with patients with DNMB, which more often received RT alone and a TPO2i-based adjuvant chemotherapy regimen.

During the past decade, increasing emphasis has been placed on the impact of molecular subgroups on patient prognosis. In most available adult studies, a predominance of non-WNT/non-SHH tumours ( $60 \%$ and almost exclusively Group 4$)$, followed by SHH-activated tumours $(\sim 30 \%)$, and very rarely WNT-activated tumours $(\sim 10 \%)$ has been reported $[6,9,22]$. Contrarily, in our study, there was a similar prevalence of non-WNT/nonSHH and SHH-MB ( $42 \%$ vs. $39 \%)$ and there were no patients with WNT-MB amongst adults with available molecular characteristics (81\%). Moreover, in our cohort, molecular subgroups did not have a significant impact on patient outcome, contrary to previous studies where SHH-MB has been linked to better survival [6,22].

The demographic, tumour and summarized treatment characteristics for adult and paediatric patients is presented in Table 1.

\subsection{Treatment Modalities}

In our cohort, 22 adult patients (85\%) had a complete macroscopic tumour resection. All but one patient received radiotherapy (RT). The one patient who did not receive RT had M0-stage disease and decided to go into palliative care after complete surgical resection of his tumour. A total of 13 patients (50\%) received RT alone and 12 patients (46\%) received RT with concomitant chemotherapy (RTCC). The radiosensitizing chemotherapy agent used in all patients was Vincristine.

Adjuvant (maintenance) chemotherapy was given to 21 adult patients (81\%). Nine patients (43\%) received a Cisplatinum and Lomustine-based regimen, ten patients (48\%) received a Cisplatinum and Etoposide-based regimen and the remaining two $(10 \%)$ received a different regimen (Table 2).

Table 2. Adult Baseline Characteristics and Treatment Regimen Based on Year of Diagnosis (Inclusively).

\begin{tabular}{|c|c|c|c|c|}
\hline & & $\begin{array}{l}\text { All Adults } \\
\mathrm{N}=26(\%)\end{array}$ & $\begin{array}{l}2006-2012 \\
N=13(\%)\end{array}$ & $\begin{array}{r}2013-2017 \\
N=13(\%)\end{array}$ \\
\hline \multicolumn{5}{|c|}{ Demographic and Tumour Characteristics } \\
\hline \multicolumn{2}{|c|}{ Median Age in Years (range) } & $29(18-53)$ & $28(20-53)$ & $31(18-51)$ \\
\hline \multirow{2}{*}{ Sex } & Male & $19(73)$ & $10(77)$ & $9(69)$ \\
\hline & Female & $7(27)$ & $3(23)$ & $4(31)$ \\
\hline \multirow{3}{*}{ Histopathology } & Classic (CMB) & $11(42)$ & $8(61.5)$ & $3(23.5)$ \\
\hline & Desmoplastic/nodular (DNMB) & $12(46)$ & $4(31)$ & $8(61.5)$ \\
\hline & Large cell/anaplastic (LCAMB) & $3(12)$ & $1(7.5)$ & $2(15)$ \\
\hline \multirow{3}{*}{$\begin{array}{l}\text { Molecular } \\
\text { Subgroup }\end{array}$} & SHH-activated * & $10(39)$ & - & $10(77)$ \\
\hline & Non-WNT/non-SHH & $11(42)$ & $9(69)$ & $2(15)$ \\
\hline & Unknown & $5(19)$ & $4(31)$ & $1(7.5)$ \\
\hline \multirow{3}{*}{$\begin{array}{l}\text { Stage at } \\
\text { Diagnosis }\end{array}$} & M0 & $14(54)$ & $5(38.5)$ & $9(69)$ \\
\hline & M2 & $1(4)$ & - & $1(7.5)$ \\
\hline & Unknown & $11(42)$ & $8(61.5)$ & $3(23)$ \\
\hline \multirow{3}{*}{$\begin{array}{l}\text { Surgical Macroscopic } \\
\text { resection }\end{array}$} & Treatment Variables & & & \\
\hline & Complete & $22(85)$ & $11(85)$ & $11(85)$ \\
\hline & Partial & $4(15)$ & $2(15)$ & $2(15)$ \\
\hline \multirow{3}{*}{ Radiotherapy } & None & $1(4)$ & - & $1(7.5)$ \\
\hline & Alone & $13(50)$ & $2(15)$ & $11(85)$ \\
\hline & With induction/concomitant chemotherapy & $12(46)$ & $11(85)$ & $1(7.5)$ \\
\hline
\end{tabular}


Table 2. Cont.

\begin{tabular}{|c|c|c|c|c|}
\hline & & $\begin{array}{l}\text { All Adults } \\
N=26(\%)\end{array}$ & $\begin{array}{l}2006-2012 \\
N=13(\%)\end{array}$ & $\begin{array}{l}2013-2017 \\
N=13(\%)\end{array}$ \\
\hline & None & $5(19)$ & $3(23.5)$ & $2(15)$ \\
\hline & Cisplatinum + Lomustine-based regimen & $9(43)$ & $9(69)$ & - \\
\hline & Cisplatinum + Lomustine ${ }^{* *}$ & $1(5)$ & $1(7.5)$ & - \\
\hline & Cisplatinum + Lomustine + Vincristine & $8(38)$ & $8(61.5)$ & - \\
\hline First Intention Maintenance & Cisplatinum + Etoposide-based regimen & $10(48)$ & - & $10(76.5)$ \\
\hline \multirow[t]{5}{*}{ Chemotherapy } & Cisplatinum + Etoposide & $1(5)$ & - & $1(7.5)$ \\
\hline & Cisplatinum + Etoposide + Cyclophosphamide & $9(43)$ & - & $9(69)$ \\
\hline & Other & $2(10)$ & $1(7.5)$ & $1(7.5)$ \\
\hline & Temozolomide & $1(5)$ & $1(7.5)$ & - \\
\hline & $\begin{array}{l}\text { Vincristine }+ \text { Cisplatinum }+ \text { Cyclophosphamide } \\
\text { alternating with Premetrexed and Gemcitabine }\end{array}$ & $1(5)$ & - & $1(7.5)$ \\
\hline
\end{tabular}

Group A: diagnosed between 2006 and 2012. Group B: diagnosed between 2013 and 2017. Percentages might not add up to 100 because of rounding. ${ }^{*}$ All adult patients with a SHH-activated pathway tumour had a TP53-wildtype variant. ${ }^{* *}$ This patient did not receive vincristine because of non-resolving neuropathies after RT.

Only three patients did not receive chemotherapy at any point in time. One patient chose to receive no adjuvant therapy, one moved out of the country before completing RT, and one patient was prescribed RT alone as his adjuvant therapy. The latter had disease recurrence after five years and was treated with palliative chemotherapy before dying seven years after his diagnosis.

Beginning in 2013, the most prescribed adjuvant chemotherapy regimen at our centre drastically drifted from a nitrosourea-based treatment to a TOP2i-based one. Because of this, we decided to compare the outcome of patients diagnosed between 2006 and 2012 with those diagnosed between 2013 and 2017. Each group had 13 patients, 11 (85\%) of which had a complete macroscopic tumour resection, and two (15\%) had a partial resection. All patients diagnosed before 2013 received RT and most of them (85\%) received RTCC. Amongst those diagnosed after 2013, all patients but one received RT, and most of those who did (85\%) received RT without concurrent chemotherapy.

A $p$-value to compare both groups based on baseline characteristics could not be calculated as $\chi^{2}$ cannot be used (most expected frequencies are less than five).

Amongst the three adult patients who had disease progression, two received salvage chemotherapy with temozolomide and one underwent surgery and an allogenic stem cell transplant.

\subsection{Survival}

The median OS of adults in our cohort was 83.5 months with an OS of $80 \%$ at five years. First line therapy had a median PFS of 67 months with a 5yPFS of 77\% (Figure 2).

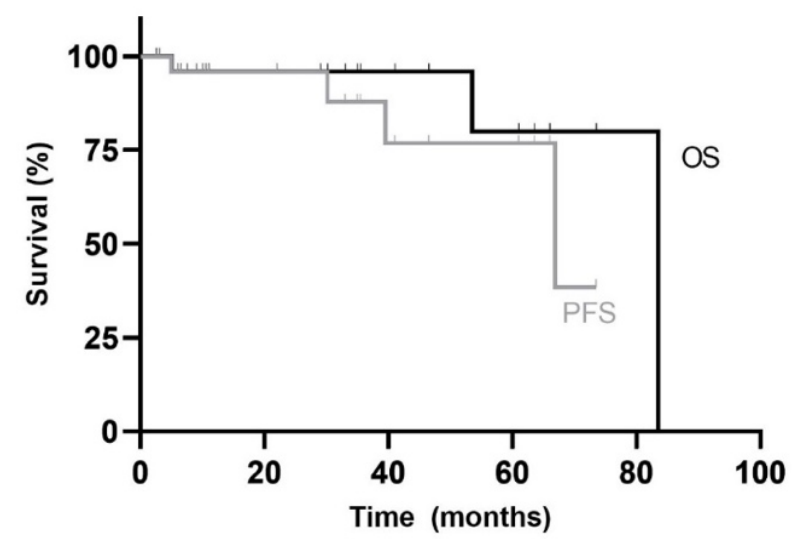

Figure 2. Kaplan-Meier overall survival (OS) and progress-free survival (PFS) curves for adult patients in the study. Median follow-up duration was 26 months (range: 3 months to 7 years). 
Table 3 summarizes the OS and PFS rates according to the different demographic, tumour and treatment characteristics. Sex, histopathology, molecular subgroup, extent of disease, quality of resection and presence or type of adjuvant chemotherapy were not significantly associated with OS or PFS (Figure 3). Only the type of RT received had prognostic value. In fact, patients who received chemotherapy alongside RT (RTCC) had a significantly better PFS compared with patients who received RT alone $(100 \%$ vs. $50 \%$ at 5 years; $p=0.033)$ and had a tendency for a better OS $(100 \%$ vs. $50 \%$ at 5 years; $p=0.157)$. A trend for better OS and PFS was observed in patients who received adjuvant chemotherapy compared to those who did not ( $p=0.155$ and $p=0.114$ respectively).

Table 3. Univariate Analysis on the Impact of Patient, Tumour and Treatment Characteristics on Overall and Progress-Free Survival in Adult Patients.

\begin{tabular}{|c|c|c|c|c|c|c|}
\hline & & $\begin{array}{c}\text { No. of Pts } \\
n=26\end{array}$ & $\begin{array}{c}5 y O S \\
(\%)\end{array}$ & $p$-Value & $\begin{array}{c}\text { 5yPFS } \\
(\%)\end{array}$ & $p$-Value \\
\hline \multicolumn{7}{|c|}{ Demographic and Tumour Characteristics } \\
\hline Sex & $\begin{array}{l}\text { Male } \\
\text { Female }\end{array}$ & $\begin{array}{c}19 \\
7\end{array}$ & $\begin{array}{c}75 \\
83.3\end{array}$ & 0.515 & $\begin{array}{c}75 \\
83.3\end{array}$ & 0.642 \\
\hline \multirow{3}{*}{ Histopathology } & Classic (CMB) & 11 & 100 & \multirow{3}{*}{0.368} & 100 & \multirow{3}{*}{0.162} \\
\hline & Desmoplastic/nodular (DNMB) & 12 & 61.1 & & 68.8 & \\
\hline & Large cell/anaplastic (LCAMB) & 3 & 100 & & 100 & \\
\hline \multirow{3}{*}{$\begin{array}{l}\text { Molecular } \\
\text { Subgroup }\end{array}$} & SHH-activated & 10 & NR & \multirow{3}{*}{0.412} & NR & \multirow{3}{*}{0.148} \\
\hline & Non-WNT/non-SHH & 11 & 80 & & 80 & \\
\hline & Unknown & 5 & NR & & NR & \\
\hline \multirow{3}{*}{$\begin{array}{c}\text { Stage at } \\
\text { Diagnosis }\end{array}$} & M0 & 14 & 92.3 & \multirow{3}{*}{0.889} & 73.8 & \multirow{3}{*}{0.496} \\
\hline & M2 & 1 & NR & & NR & \\
\hline & Unknown & 11 & 80 & & 80 & \\
\hline \multicolumn{7}{|c|}{ Treatment Variables } \\
\hline Surgical Macroscopic & Complete & 22 & 79.2 & \multirow{2}{*}{0.655} & 74.8 & \multirow{2}{*}{0.527} \\
\hline Resection & Partial & 4 & NR & & NR & \\
\hline \multirow{2}{*}{ Radiotherapy } & Alone & 13 & 50 & \multirow[b]{2}{*}{0.157} & 50 & \multirow{2}{*}{0.033} \\
\hline & With induction/concomitant chemotherapy & 12 & 100 & & 100 & \\
\hline Adjuvant & Yes & 21 & 80 & \multirow{2}{*}{0.155} & 77.9 & \multirow{2}{*}{0.114} \\
\hline Chemotherapy & No & 5 & 66.7 & & 66.7 & \\
\hline Type of Adjuvant & Cisplatinum + Lomustine-based regimen & 9 & 75 & \multirow{3}{*}{-} & 80 & \multirow{3}{*}{0.410} \\
\hline Chemotherapy (First & Cisplatinum + Etoposide-based regimen & 10 & NR & & NR & \\
\hline Intention) & Other & 2 & NR & & NR & \\
\hline
\end{tabular}

NR: not reached.
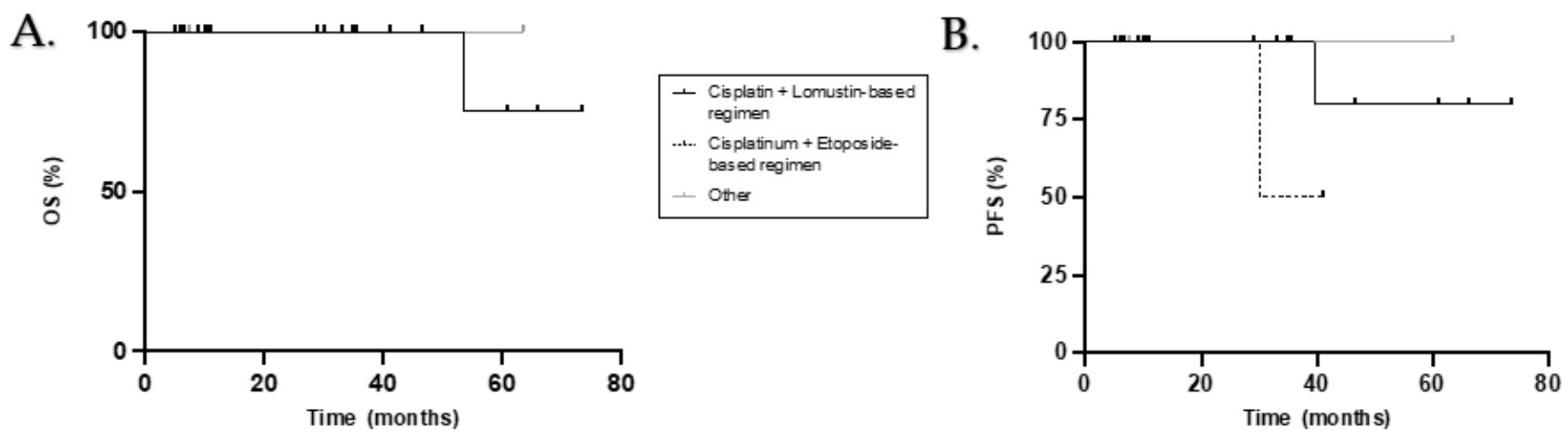

Figure 3. Kaplan-Meier overall survival (A) and progress-free survival (B) curves for adult patients who received adjuvant chemotherapy according to treatment regimen.

When comparing both groups, we highlight a tendency for better PFS in patients diagnosed from 2006 to $2012(p=0.087)$ and no significant difference for OS between the two groups $(p=0.317)$ (Figure 4$)$. 
A.

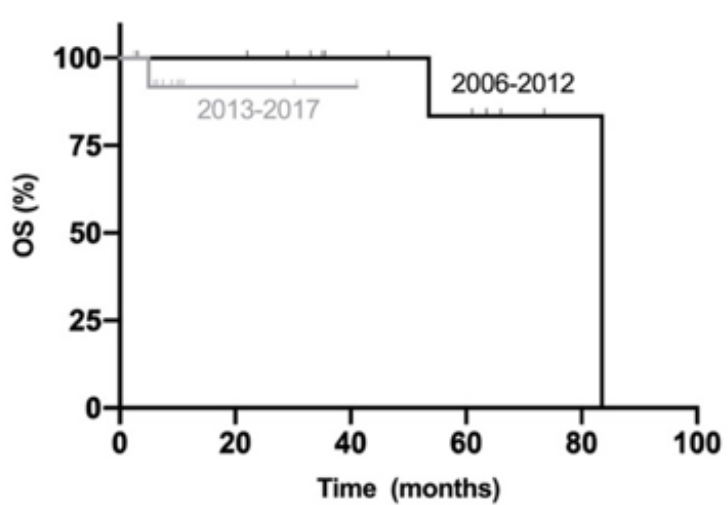

B.

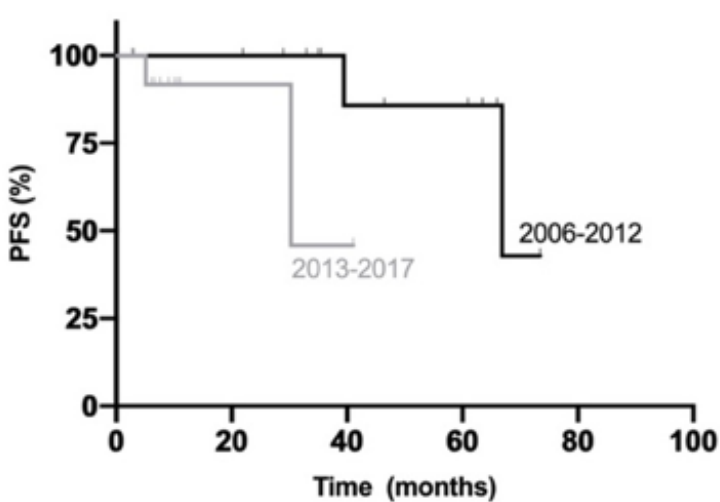

Figure 4. Kaplan-Meier overall survival (A) and progress-free survival (B) curves for all adult patients included in this study according to year of diagnosis.

\section{Discussion}

Our study comprises the most recent adult MB patient series in North America and is the only series consisting of primarily French-Canadian patients. All patients were followed at the main reference centre for adult $\mathrm{MB}$ in the province of Quebec. Given the rarity of $\mathrm{MB}$ in the adult population, this review stands as one of the biggest ones of its kind in current literature.

The characteristics of the children treated at the CHUM was included in Table 1 for reference and comparison to the paediatric population that has been described in literature, as well as to the adult population specific to this study. Children were not included in our discussion as the scope of this study is limited to adults. Furthermore, the information on the treatment regimen used in children was limited as they were typically seen at our centre for radiotherapy only.

\subsection{Survival}

Adult MB patients in the present study had better OS and PFS than typically described in the available literature. In multiple retrospective adult MB series analysing 13 to 206 patients, the 5yOS ranged between 40 and $84 \%$ and the 5yPFS between 32 and $63 \%$ [1,8,9]. In our cohort, the $5 \mathrm{yOS}$ was $80 \%$ and the $5 \mathrm{yPFS}$ was $77 \%$.

\subsection{Impact of Demographic and Tumour Factors}

In our study, age, sex and histological subtypes had no impact on the prognosis of adult MB patients. Therefore, we believe that our outstanding OS and PFS is due, in part, to the high prevalence of $\mathrm{SHH}$-activated tumours in our cohort when compared to current literature.

Advanced disease at diagnosis is a recognized prognostic factor in children, but it is of debatable relevance in adults [19]. Several adult studies have observed that there is no correlation between M-stage at diagnosis and patient outcome [11,12,19]. In our study, this was difficult to evaluate as information was unavailable for $42 \%$ of patients; CSF analysis was lacking, either because it was done at another centre and the results were not reported, or because it was never performed. Following a review of their imaging studies, it was determined that no patient in the unavailable M-stage category had macroscopic metastasis (M2-M4) and we can now assume, based on our excellent OS and PFS, that CSF was negative for most of them. However, as obtaining CSF in all patients is Level I A evidence, we are committed to improving this aspect of patient care [23].

\subsection{Role of the Different Treatment Variables}

Adults continue to be treated with regimens extrapolated from paediatric protocols despite the differences between adult and paediatric MB since the rareness of the tumour hinders prospective studies and randomized control trials. Maximal safe surgical resection 
aiming for gross total tumour extraction and RT with CSI are recognized to be standardof-care for adults [23-27]. However, the advantage of chemotherapy during or after RT remains controversial $[3,12,23,27,28]$.

In our study, we demonstrated that $38 \%$ of adult patients received a full treatment including RT, concomitant chemotherapy (RTCC) and adjuvant chemotherapy in spite of their age, comorbidities and disease extent. All patients but one received RT and nearly half of these patients received concomitant chemotherapy (Vincristine). Patients who received RT alone had significantly worse PFS (5yPFS 50\% vs. $100 \%, p=0.033$ ) when compared with patients who received RTCC. The same trend was observed with regards to OS (5yOS $50 \%$ vs. $100 \%, p=0.157)$.

We did not demonstrate a significant advantage in the administration of maintenance chemotherapy, but we observed a tendency for better PFS and OS in patients who did receive it (5yOS $80 \%$ vs. $67 \%, p=0.155 ; 5 y P F S 78 \%$ vs. $67 \%, p=0.114$ ). This correlates with the many available studies and guidelines that suggest its use in all adult patients regardless of risk stratification [17,19,23,29-31]. Patients who received RTCC followed by maintenance chemotherapy had statistically better OS and PFS when compared with patients who received RT alone followed by maintenance chemotherapy, regardless of chemotherapy agent ( $p=0.046$ and $p=0.023$ respectively). We did not demonstrate a clear advantage of a Cisplatinum and Lomustine based regimen when compared with Cisplatinum and Etoposide but observed a tendency for a better PFS in patients treated with the former agents $(p=0.087)$.

\subsection{Limitations}

The retrospective nature of our review and its small sample size comprise its major limitations. However, given the rarity of $\mathrm{MB}$ in the adult population, this study remains one of the most important of its kind in current literature. Furthermore, this review revealed a lack of complete workup in patients prior to treatment (i.e., CSF analysis). As explained above, this made it more difficult to precisely classify patients according to their stage at diagnosis (i.e., M0 vs. M1 disease). As there is high level evidence supporting complete workup in patients prior to treatment, we are committed to improving this aspect of patient care [23]. Still, we have demonstrated an excellent OS and PFS in our adult population.

\section{Conclusions}

Our adult MB population has an outstanding OS and PFS when compared to children and adults in most available studies, despite most patients not receiving a full treatment regimen when compared to paediatric standards (surgical resection, RT, RTCC and adjuvant chemotherapy). The demographic and tumor characteristics did not have a discernable impact on prognosis. Radiotherapy with concurrent chemotherapy (Vincristine) had a significantly favourable impact on PFS and a tendency for better OS. We observed a trend for a more favourable outcome in patients who received adjuvant chemotherapy, especially with a Cisplatinum, Lomustine and Vincristine regimen. Prospective studies are required to further evaluate the roles of RTCC and adjuvant chemotherapy.

Author Contributions: M.C.Q., M.F.: conceptualization, methodology, validation, formal analysis, investigation, resources, data curation, writing — original draft preparation and writing-review and editing. K.B., É.L.B., B.L., J.-P.B., L.G.M., D.R., C.M., C.L., F.B., R.M., M.F.: methodology, supervision and writing-review and editing. All authors have read and agreed to the published version of the manuscript.

Funding: This research received no external funding.

Institutional Review Board Statement: The study was conducted according to the guidelines of the Declaration of Helsinki, and approved by the Ethics Committee of the Research Centre of the Centre universitaire de l'Université de Montréal (CrCHUM) (protocol code 18.086; date of approval: 14 June 2018).

Informed Consent Statement: Not applicable. 
Data Availability Statement: The data presented in this study are available on request from the corresponding author. The data are not publicly available due to privacy and ethical reasons.

Conflicts of Interest: The authors declare no conflict of interest.

\section{References}

1. Abacioglu, U.; Uzel, O.; Sengoz, M.; Turkan, S.; Ober, A. Medulloblastoma in Adults: Treatment Results and Prognostic Factors. Int. J. Radiat. Oncol. 2002, 54, 855-860. [CrossRef]

2. Brandes, A.A.; Paris, M.K. Review of the Prognostic Factors in Medulloblastoma of Children and Adults. Crit. Rev. Oncol. Hematol. 2004, 50, 121-128. [CrossRef] [PubMed]

3. Silvani, A.; Gaviani, P.; Lamperti, E.; Botturi, A.; Dimeco, F.; Franzini, A.; Ferroli, P.; Fariselli, L.; Milanesi, I.; Erbetta, A.; et al. Adult Medulloblastoma: Multiagent Chemotherapy with Cisplatinum and Etoposide: A Single Institutional Experience. J. Neuro-Oncol. 2012, 106, 595-600. [CrossRef] [PubMed]

4. Giordana, M.T.; Cavalla, P.; Dutto, A.; Borsotti, L.; Chiò, A.; Schiffer, D. Is Medulloblastoma the Same Tumor in Children and Adults? J. Neuro-Oncol. 1997, 35, 169-176. [CrossRef]

5. Li, Q.; Dai, Z.; Cao, Y.; Wang, L. Comparing Children and Adults with Medulloblastoma: A SEER Based Analysis. Oncotarget 2018, 9, 30189-30198. [CrossRef]

6. Zhao, F.; Ohgaki, H.; Xu, L.; Giangaspero, F.; Li, C.; Li, P.; Yang, Z.; Wang, B.; Wang, X.; Wang, Z.; et al. Molecular Subgroups of Adults Medulloblastoma: A Long-Term Single-Institution Study. Neuro-Oncology 2016, 18, 982-990. [CrossRef]

7. Ang, C.; Hauerstock, D.; Guiot, M.C.; Kasumjanova, G.; Roberge, D.; Kavan, P.; Muanza, T. Characteristics and outcomes of medulloblastoma in adults. Pediatr. Blood Cancer 2008, 51, 603-607. [CrossRef]

8. Carrie, C.; Lasset, C.; Alapetite, C.; Haie-Meder, C.; Hoffstetter, S.; Demaille, M.C.; Kerr, C.; Wagner, J.P.; Lagrange, J.L.; Maire, J.P. Multivariate Analysis of Prognostic Factors in Adult Patients with Medulloblastoma. Retrospective Study of 156 Patients. Cancer 1994, 74, 2352-2360. [CrossRef]

9. Kool, M.; Korshunov, A.; Remke, M.; Jones, D.T.; Schlanstein, M.; Northcott, P.A.; Cho, Y.J.; Koster, J.; Schouten-van Meeteren, A.; van Vuurden, D.; et al. Molecular Subgroups of Medulloblastoma: An International Meta-Analysis of Transcriptome, Genetic Aberrations, and Clinical Data of WNT, SHH, Group 3, and Group 4 Medulloblastomas. Acta Neuropathol. 2012, 123, $473-484$. [CrossRef]

10. Atalar, B.; Ozsahin, M.; Call, J.; Napieralska, A.; Kamer, S.; Villa, S.; Erpolat, P.; Negretti, L.; Lassen-Ramshad, Y.; Onal, C.; et al. Treatment Outcome and Prognostic Factors for Adult Patients with Medulloblastoma: The Rare Cancer Network (RCN) Experience. Radiother. Oncol. J. Eur. Soc. Ther. Radiol. Oncol. 2018, 127, 96-102. [CrossRef]

11. BKann, H.; Lester-Coll, N.H.; Park, H.S.; Yeboa, D.N.; Kelly, J.R.; Baehring, J.M.; Becker, K.P.; Yu, J.B.; Bindra, R.S.; Roberts, K.B. Adjuvant Chemotherapy and Overall Survival in Adult Medulloblastoma. Neuro-Oncology 2017, 19, $259-269$.

12. Chan, A.W.; Tarbell, N.J.; Black, P.M.; Louis, D.N.; Frosch, M.P.; Ancukiewicz, M.; Chapman, P.; Loeffler, J.S. Adult Medulloblastoma: Prognostic Factors and Patterns of Relapse. Neurosurgery 2000, 47, 623-632.

13. Tait, D.M.; Thornton-Jones, H.; Bloom, H.J.; Lemerle, J.; Morris-Jones, P. Adjuvant Chemotherapy for Medulloblastoma: The First Multi-Centre Control Trial of the International Society of Paediatric Oncology (SIOP I). Eur. J. Cancer 1990, 26, 464-469. [CrossRef]

14. Weil, M.D.; Lamborn, K.; Edwards, M.S.; Wara, W.M. Influence of a Child's Sex on Medulloblastoma Outcome. JAMA 1998, 279, 1474-1476. [CrossRef]

15. Duffner, P.K.; Horowitz, M.E.; Krischer, J.P.; Friedman, H.S.; Burger, P.C.; Cohen, M.E.; Sanford, R.A.; Mulhern, R.K.; James, H.E.; Freeman, C.R. Postoperative Chemotherapy and Delayed Radiation in Children Less than Three Years of Age with Malignant Brain Tumors. N. Engl. J. Med. 1993, 328, 1725-1731. [CrossRef] [PubMed]

16. Curran, E.K.; Le, G.M.; Sainani, K.L.; Propp, J.M.; Fisher, P.G. Do Children and Adults Differ in Survival from Medulloblastoma? A Study from the SEER Registry. J. Neuro-Oncol. 2009, 95, 81-85. [CrossRef] [PubMed]

17. De, B.; Beal, K.; de Braganca, K.C.; Souweidane, M.M.; Dunkel, I.J.; Khakoo, Y.; Gilheeney, S.W.; DeAngelis, L.M.; Menzel, P.; Patel, S.H.; et al. Long-Term Outcomes of Adult Medulloblastoma Patients Treated with Radiotherapy. J. Neuro-Oncol. 2018, 136, 95-104. [CrossRef]

18. Rutkowski, S.; von Hoff, K.; Emser, A.; Zwiener, I.; Pietsch, T.; Figarella-Branger, D.; Giangaspero, F.; Ellison, D.W.; Garre, M.L.; Biassoni, V.; et al. Survival and Prognostic Factors of Early Childhood Medulloblastoma: An International Meta-Analysis. J. Clin. Oncol. Off. J. Am. Soc. Clin. Oncol. 2010, 28, 4961-4968. [CrossRef]

19. Kocakaya, S.; Beier, C.P.; Beier, D. Chemotherapy Increases Long-Term Survival in Patients with Adult Medulloblastoma-A LiteratureBased Meta-Analysis. Neuro-Oncology 2016, 18, 408-416. [CrossRef] [PubMed]

20. Lai, R. Survival of Patients with Adult Medulloblastoma: A Population-Based Study. Cancer 2008, 18, 1568-1574. [CrossRef] [PubMed]

21. Padovani, L.; Sunyach, M.P.; Perol, D.; Mercier, C.; Alapetite, C.; Haie-Meder, C.; Hoffstetter, S.; Muracciole, X.; Kerr, C.; Wagner, J.P.; et al. Common Strategy for Adult and Pediatric Medulloblastoma: A Multicenter Series of 253 Adults. Int. J. Radiat. Oncol. Biol. Phys. 2007, 68, 433-440. [CrossRef]

22. Northcott, P.A.; Jones, D.T.; Kool, M.; Robinson, G.W.; Gilbertson, R.J.; Cho, Y.J.; Pomeroy, S.L.; Korshunov, A.; Lichter, P.; Taylor, M.D.; et al. Medulloblastomics: The End of the Beginning. Nat. Rev. Cancer 2012, 12, 818-834. [CrossRef] [PubMed] 
23. Franceschi, E.; Hofer, S.; Brandes, A.A.; Frappaz, D.; Kortmann, R.D.; Bromberg, J.; Dangouloff-Ros, V.; Boddaert, N.; Hattingen, E.; Wiestler, B.; et al. EANO-EURACAN Clinical Practice Guideline for Diagnosis, Treatment, and Follow-Up of Post-Pubertal and Adult Patients with Medulloblastoma. Lancet Oncol. 2019, 20, e715-e728. [CrossRef]

24. Khalil, E.M. Treatment Results of Adults and Children with Medulloblastoma NCI, Cairo University Experience. J. Egypt. Natl. Cancer Inst. 2008, 20, 175-186.

25. Packer, R.J.; Gajjar, A.; Vezina, G.; Rorke-Adams, L.; Burger, P.C.; Robertson, P.L.; Bayer, L.; LaFond, D.; Donahue, B.R.; Marymont, M.H.; et al. Phase III Study of Craniospinal Radiation Therapy Followed by Adjuvant Chemotherapy for Newly Diagnosed Average-Risk Medulloblastoma. J. Clin. Oncol. Off. J. Am. Soc. Clin. Oncol. 2006, 24, 4202-4208. [CrossRef]

26. Packer, R.J.; Pfister, S.M. Medulloblastoma. In Encyclopedia of Neuroscience; Squire, L.R., Ed.; Academic Press: Cambridge, MA, USA, 2009; pp. 703-711.

27. Selek, U.; Zorlu, F.; Hurmuz, P.; Cengiz, M.; Turker, A.; Soylemezoglu, F.; Gurkaynak, M. Craniospinal Radiotherapy in Adult Medulloblastoma. Strahlenther. Onkol. Organ. Dtsch. Rontgenges. 2007, 183, 236-240. [CrossRef]

28. Greenberg, H.S.; Chamberlain, M.C.; Glantz, M.J.; Wang, S. Adult Medulloblastoma: Multiagent Chemotherapy. Neuro-Oncology 2001, 31, 29-34. [CrossRef]

29. Call, J.A.; Naik, M.; Rodriguez, F.J; Giannini, C.; Wu, W.; Buckner, J.C.; IParney, F.; Laack, N.N. Long-Term Outcomes and Role of Chemotherapy in Adults with Newly Diagnosed Medulloblastoma. Am. J. Clin. Oncol. 2014, 37, 1-7. [CrossRef]

30. Franceschi, E.; Bartolotti, M.; Paccapelo, A.; Marucci, G.; Agati, R.; Volpin, L.; Danieli, D.; Ghimenton, C.; Gardiman, M.P.; Sturiale, C.; et al. Adjuvant Chemotherapy in Adult Medulloblastoma: Is it an Option for Average-Risk Patients? J. Neuro-Oncol. 2016, 128, 235-240. [CrossRef]

31. Herlinger, U.; Steinbrecher, A.; Rieger, J.; Hau, P.; Kortmann, R.D.; Meyermann, R.; Schabet, M.; Bamberg, M.; Dichgans, J.; Bogdahn, U.; et al. Adult Medulloblastoma: Prognostic Factors and Response to Therapy at Diagnosis and at Relapse. J. Neurol. 2005, 252, 291-299. [CrossRef] 